
Oceanological and Hydrobiological Studies International Journal of Oceanography and Hydrobiology
Vol. XXXVII, No.2

Institute of Oceanography

(107-118)

University of Gdańsk

ISSN 1730-413X

2008

eISSN 1897-3191

DOI 10.2478/v10009-008-0001-5

Original research paper

\title{
Effects of cooling water discharges from a power plant on reservoir water quality
}

\author{
Eligiusz Kowalski ${ }^{1}$, Jerzy Mazierski \\ Institute of Environmental Engineering, Polish Academy of Sciences \\ ul. M. Sktodowskiej-Curie 34, 41-800 Zabrze, Poland
}

Key words: cooling system, water quality, water temperature

\begin{abstract}
The use of natural or artificial water reservoirs by thermal power plants for cooling purposes alterswater ecosystems. Water ecosystems are mainly subjected to the abiotic influences of higher temperature and increased mixing. This study presents the thermal and oxygen conditions in a lake used for cooling water as well as the chemical changes occurring in it. There is a spatial differentiation in the temperature of the water surface over time periods (in summer and winter).

The vertical water temperature changes were definitely different from those of natural, unaffected lakes. Apart from a higher average water temperature, typical mixing and stratification periods were not observed. This apparently affected the dissolved oxygen conditions. The observed absence of a dissolved oxygen deficit resulted from the lack of a thermocline, which positively affected water quality. As a result, the two anthropogenic factors, i.e., the discharge of warm water and increased mixing, have flattened the negative effects on the lake. A new characteristic equilibrium for this lake was established. Single factors have been compensated for by this equilibrium. A relationship between temperature and biomass concentration was observed. The trophic state index (TSI) values permit classifying Rybnik Reservoir as a eutrophic lake.
\end{abstract}

\footnotetext{
${ }^{1}$ Corresponding author: kowalski@ipis.zabrze.pl 


\section{INTRODUCTION}

Water is used in many industrial applications as a cooling agent. The largest industrial users of cooling water are thermal power plants. A summary report in 1996 about cooling system utilities owned by power plants (EEI 1996) states that $44 \%$ of US thermal-electric generating capacity uses once-through cooling systems. Such systems are supplied by large volumes of water from a river, lake, estuary, or ocean that are pumped through the condenser and returned to the same or a nearby body of water. About $50 \%$ of US generating capacity utilize closed-cycle cooling systems (cooling towers $-35 \%$; cooling ponds or lakes $-15 \%)$. In a closed-cycle system, water is supplied by a cooling tower basin, cooling pond, or cooling lake, pumped to the condenser and returned to the basin, pond, or lake. Another 5\% of US generating capacity uses a combination of once-through cooling and closed-cycle systems or operates in a mixed mode (Veil at al. 1999, Veil 2000).

The environmental impact (Bloemkolk and van der Schaff 1996) related to the use and discharge of cooling water consists of the emission of heat which affects both the water temperature and dissolved oxygen concentration, resulting in:

- the disturbance of the natural surface water ecosystem due to suction and the subsequent destruction of live organisms (microorganisms, fish, etc.) into the cooling water pipes, channels, and heat exchange system;

- the discharge of conditioning chemicals used to prevent biological and physical fouling of the cooling system (e.g. biocides, dispersing and anticorrosive agents, or their degradation products);

- the contamination of surface waters by process chemicals leaking into cooling water (oil, aromatics, organochlorine).

The aim of the current paper was to present the effects of heated water discharge and water circulation on the temperature distribution (spatial and vertical), oxygen and biomass concentrations, and trophic state index of the reservoir.

\section{MATERIALS AND METHODS}

Rybnik Reservoir was built as the element of a cooling system for a nearby power plant. The Ruda River discharges waters into the reservoir. The mean discharge of the river is approximately $2.57 \mathrm{~m}^{3} \mathrm{~s}^{-1}$. The total reservoir area is 555 ha, its average depth is $5.4 \mathrm{~m}$, and total volume is $24 \times 10^{6} \mathrm{~m}^{3}$. The mean residence time is 108 days.

The water intake for cooling and the discharge of the heated water is approximately $32.2 \mathrm{~m}^{3} \mathrm{~s}^{-1}$. 
The reservoir can be divided into three parts: the dam zone with a depth of $12 \mathrm{~m}$, the pelagic zone with a depth of $4-7 \mathrm{~m}$, and the discharge zone that is $4 \mathrm{~m}$ deep.

The water quality of the Rybnik Reservoir was monitored in 2004. Water samples were collected every month from two zones (regions): the discharge and dam regions at stations 1 and 2, respectively (Fig. 1). The water temperature and dissolved oxygen vertical profile were measured at $1 \mathrm{~m}$ intervals. Secchi disk depth was also measured. Water samples were collected from the surface layer and the nutrient concentrations were determined in the laboratory with commonly-used methods (Standard Methods 1981). The total biomass in the reservoir water was determined as volatile suspended solids (Standard Methods 1981).

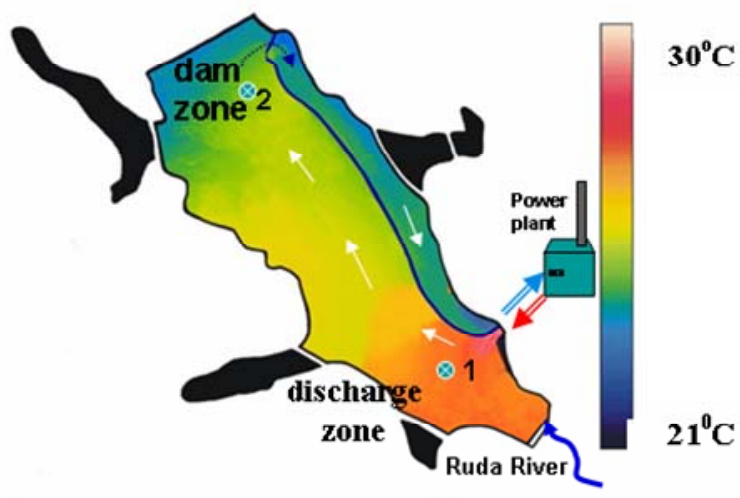

Fig. 1. Surface layer water temperature in Rybnik Reservoir in summer 2004.

In order to explain the effect of nutrient concentration on water blooms, the Carlson Trophic State Index (TSI) was used. The experimental values of Secchi disk depth, and total nitrogen and phosphorus concentrations were recalculated with the following formulas (Carlson 1977; Kratzer and Brezonik 1981):

where:

$$
\begin{gathered}
\text { TSI(SD) }=60-14.41 \ln (\mathrm{SD}) \\
\text { TSI(CHL) }=9.81 \ln (\mathrm{CHL})+30.6 \\
\text { TSI(TP) }=14.42 \ln (\mathrm{TP})+4.15 \\
\mathrm{TSI}(\mathrm{TN})=54.45+14.43 \ln (\mathrm{TN})
\end{gathered}
$$

SD - Secchi disk depth [m];

CHL - chlorophyll concentration $\left[\mu \mathrm{g} \mathrm{dm}^{-3}\right]$;

TP - total phosphorus concentration $\left[\mu \mathrm{g} \mathrm{dm}^{-3}\right]$;

$\mathrm{TN}$ - total nitrogen concentration $\left[\mathrm{mg} \mathrm{dm}^{-3}\right]$. 


\section{RESULTS AND DISCUSSION}

The continuous discharge of heated water has a distinct impact on the reservoir's thermal conditions. In natural and artificial reservoirs, water temperature is strongly dependent on atmospheric air temperature. In cooling ponds, water temperature also depends on the flow and temperature of the discharged heated water.

The discharge of heated water into a reservoir causes the formation of two layers: an upper warm layer and a lower cold one. The upper layer temperature is modified by evaporation and heat convection to the water and the atmospheric air. Thermophotography pictures were taken to show the distribution of temperature in the upper surface layer of the cooling reservoir (Kostecki et al. 2004, Kostecki 2005).

In winter as well as in summer, it is possible to divide the cooling reservoir into two main parts: the upper, shallow, warm part, where the heated water is discharged, and the lower, deep part, where water temperature decreases (Figs. 1 and 2).

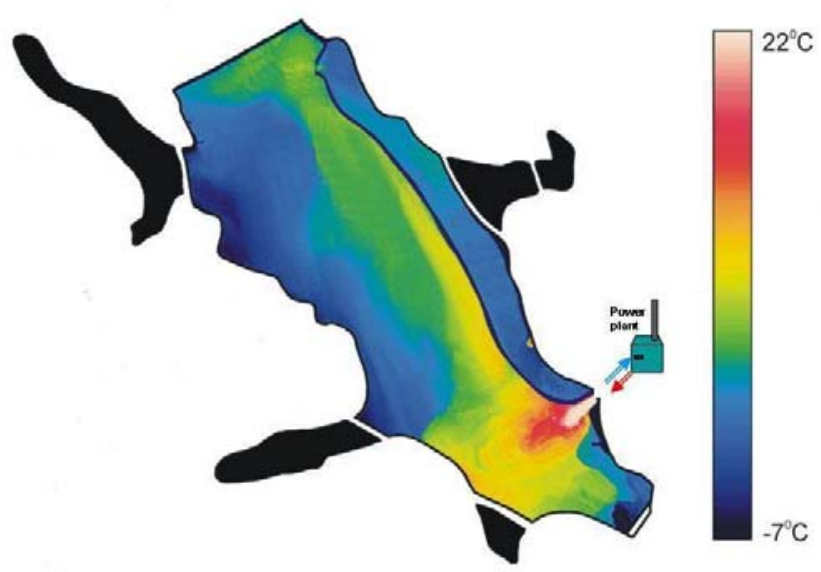

Fig. 2. Surface layer water temperature in Rybnik Reservoir in winter 2004.

It was noted, that in winter the heated (warmer) water flows near the steering embankments (dike), while the northern part of the reservoir was used only to a limited degree. In summer the water flow was more uniform and the reservoir area close to the left shore was also used. Somewhat higher water temperatures were observed in the discharge zone, and these decreased with distance and increasing water depth. 
During the investigated period of four years, no ice cover appeared, and a rather low water temperature of $6.4^{\circ} \mathrm{C}$ was observed in January 2004 close to the dam. The water temperature in the discharge zone ranged from 12 to $16^{\circ} \mathrm{C}$. The average monthly water temperature in 2004 in both sectors is presented in Fig. 3. The maximum temperature difference between the heated discharge and the dam zone was $8.5^{\circ} \mathrm{C}$ in winter.

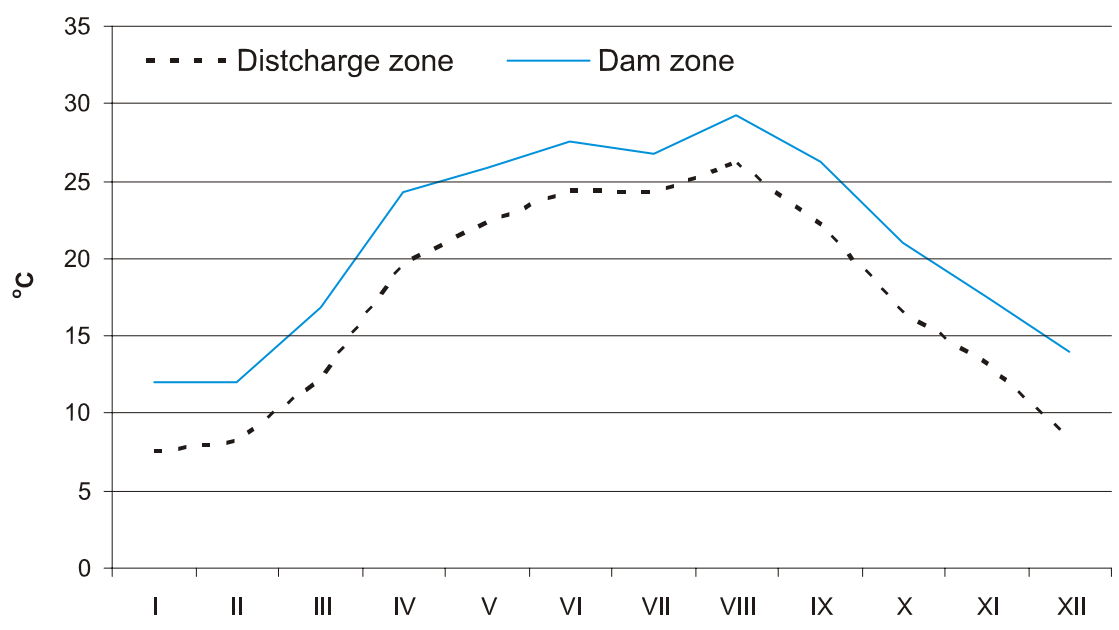

Months 2004

Fig. 3. Temperature of the surface water layer in Rybnik Reservoir.

The investigation of the temperature and dissolved oxygen vertical distribution distinctly reflect the specific conditions in Rybnik Reservoir. Its specific attribute is the absence of spring or fall mixing phenomena. In the dam sector the temperature values were similar, independently of depth. Only in spring and early summer (April-July or March-June) was the thermocline visible (Fig. 4). The temperature differences were unstable, and equalization was observed in the water column as the result of intensive wind water mixing.

In Rybnik Reservoir, only one short stagnation period was observed in the "cold" dam sector. Such conditions are typical for lakes in a tropical climate (Amarasinghe et al. 2002, Rai 2000) and for other heated lakes (Zdanowski et al. 1991). Under the temperate climate conditions of Poland, two distinct mixing and stagnation periods are expected (Kostecki 2004). 


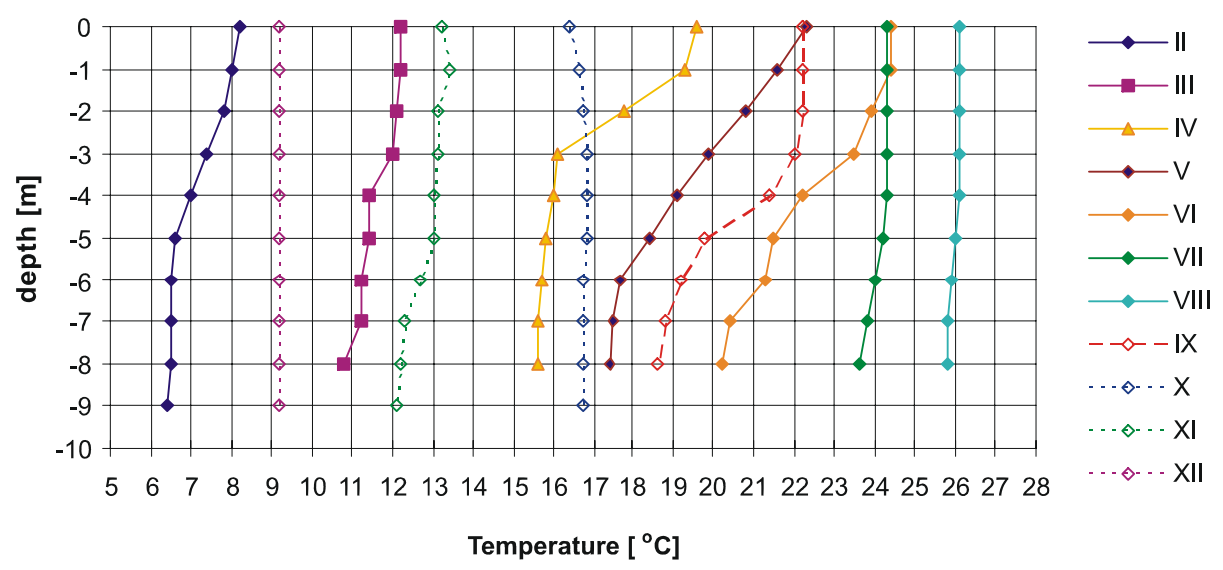

Fig. 4. Monthly temperature changes in the water column (dam zone) in 2004.

On the opposite side of the reservoir, in the upper part where heated water is discharged, significant temperature differences between the surface and bottom layer were observed, as is presented in Fig. 5. This phenomenon can be explained by the skimming of the water layers. The temperature gradients in both areas are presented in Fig. 6.

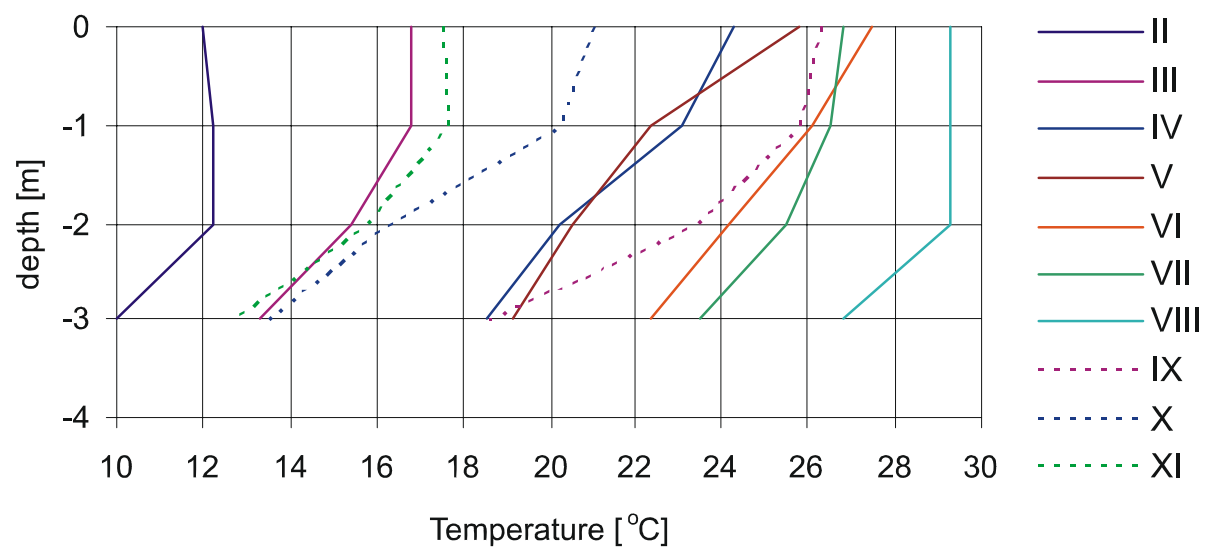

Fig. 5. Monthly temperature changes in the water column (discharge zone) in 2004. 


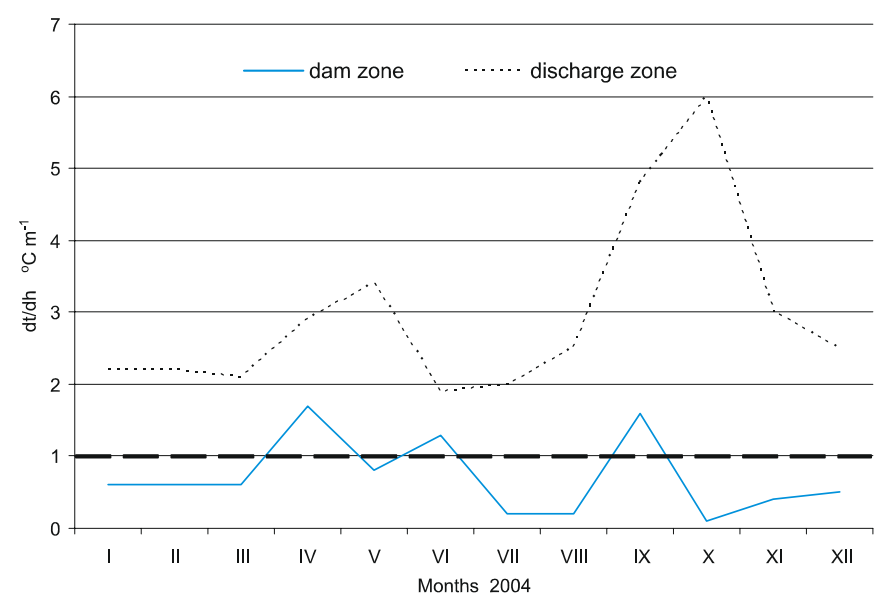

Fig. 6. Seasonal maximum temperature gradient in the water column.

The mixing and stagnation periods affect the dissolved oxygen concentration in the water. Obviously, during the mixing period the water is well aerated. On the other hand, oxygen deficiencies can appear during stagnation periods. In 2004 at the end of the stagnation period (June, July) in the region close to the dam at the depth of $9 \mathrm{~m}$, the dissolved oxygen concentration dropped to $0.2 \mathrm{mg} \mathrm{dm}^{-3}$ (Fig. 7). This differs from unheated reservoirs where oxygen depletion takes place in summer at depths as shallow as $5-6 \mathrm{~m}$ (Kostecki 2001).

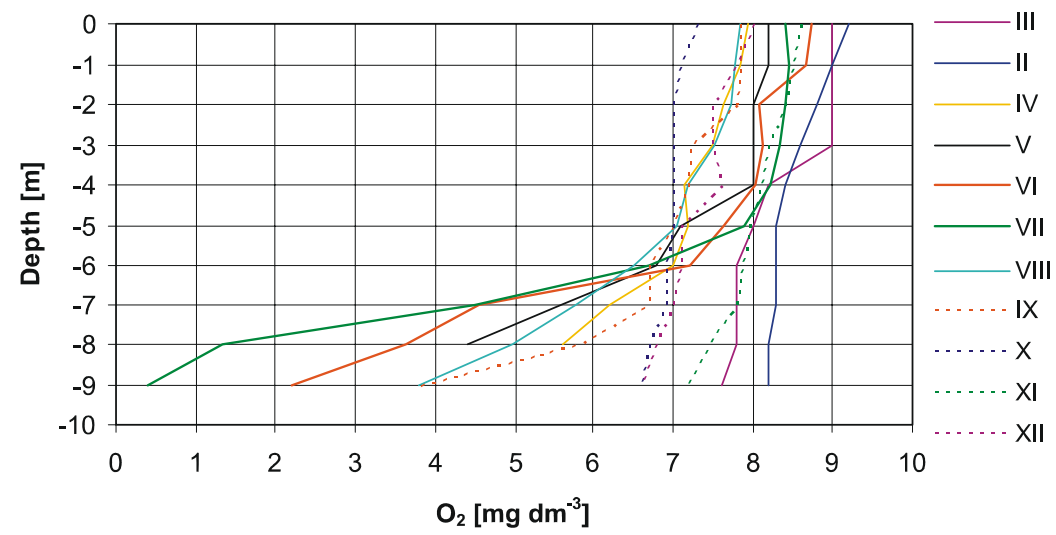

Fig. 7. Monthly DO changes in the water column (dam zone) in 2004. 
In the case of the investigated reservoir, intense water circulation and mixing caused by the pumping system of the power plant prevented dissolved oxygen depletion. In the warm water discharge zone, with a relatively high degree of mixing, no oxygen deficiency was detected irrespectively of the higher water temperature and consecutively lower oxygen solubility under such conditions (Fig. 8).

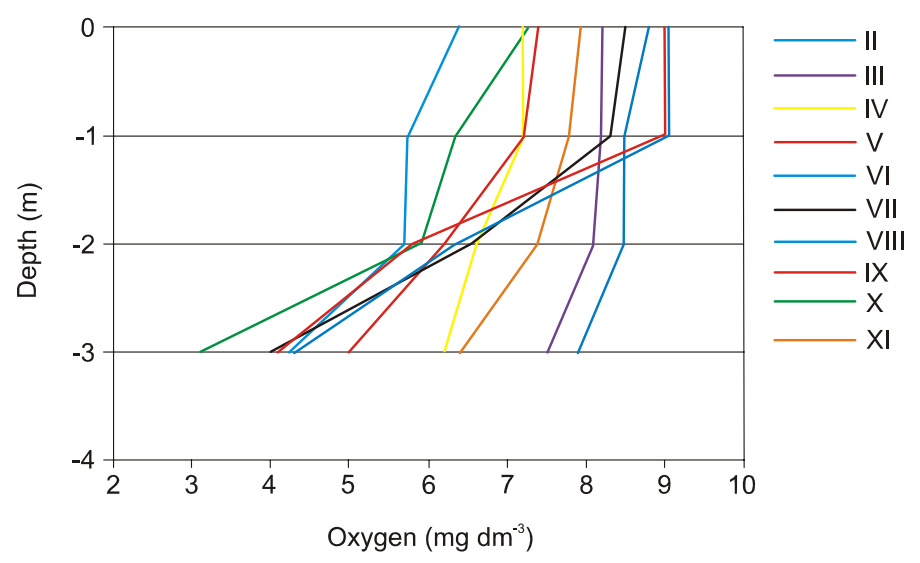

Fig. 8. Monthly DO changes in the water column (discharge zone) in 2004.

In summer both in the discharge and dam areas, oxygen supersaturation of the surface layer was observed. This phenomenon could be explained by green algae blooms. In Rybnik Reservoir water blooms occur every year in summer. The results of biomass concentrations measured in 2004 are presented in Fig. 9. The increase of plankton biomass was observed in the period from March to November. Particularly intense algae growth was observed in the discharge area between May and September. This can be explained by the warm water temperature under calm weather conditions and the corresponding stratification (Hense et al. 2006, Zdanowski et al. 1991).

The values of Trophic State Index are presented in Figs. 10 and 11. On the basis of the values of TSI, Rybnik Reservoir can be classified as a eutrophic or hypereutrophic basin. Both in the discharge and dam area, the TSI calculated based on total phosphorus was higher than the TSI (TN) and TSI (SD).

The nitrogen and phosphate concentrations are significant factors influencing Secchi disk depth, but other effects cannot be ignored (Gołdyn et al. 2003). This was confirmed by the high correlation coefficient between TSI (TN) and TSI (SD) $\mathrm{r}^{2}$ of 0.5389 (Fig. 12). 


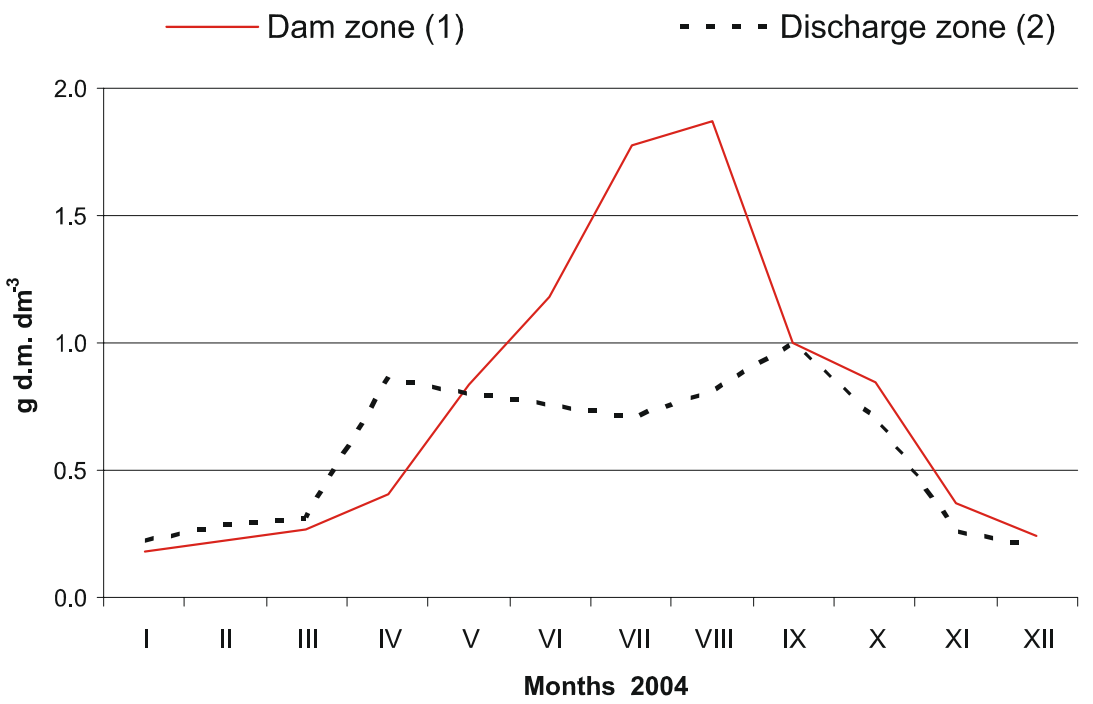

Fig. 9. Biomass of planktonic organisms in Rybnik Reservoir.

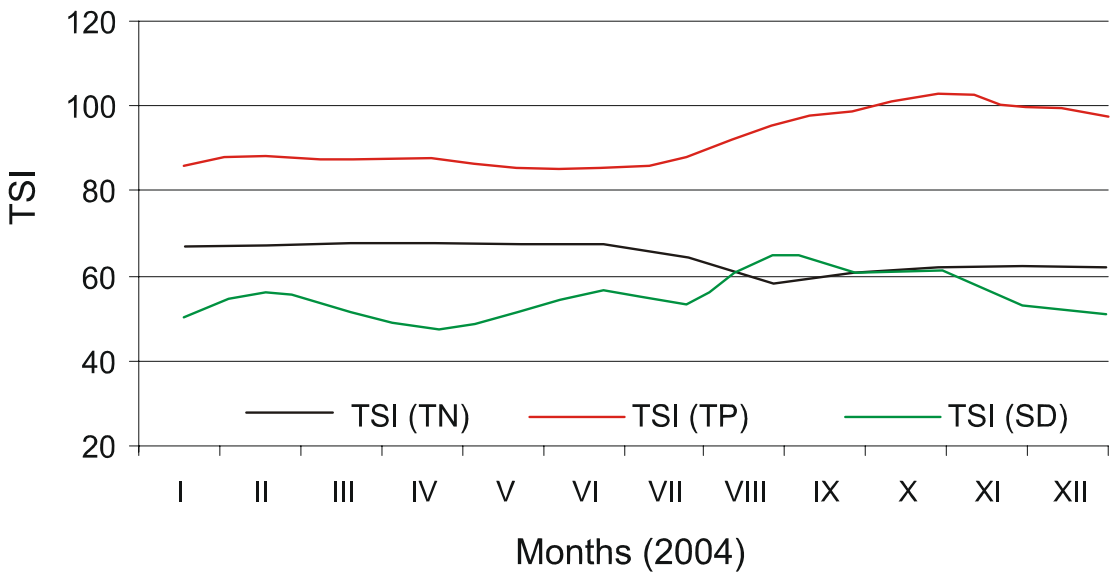

Fig. 10. Seasonal changes of TSI in the dam zone. 


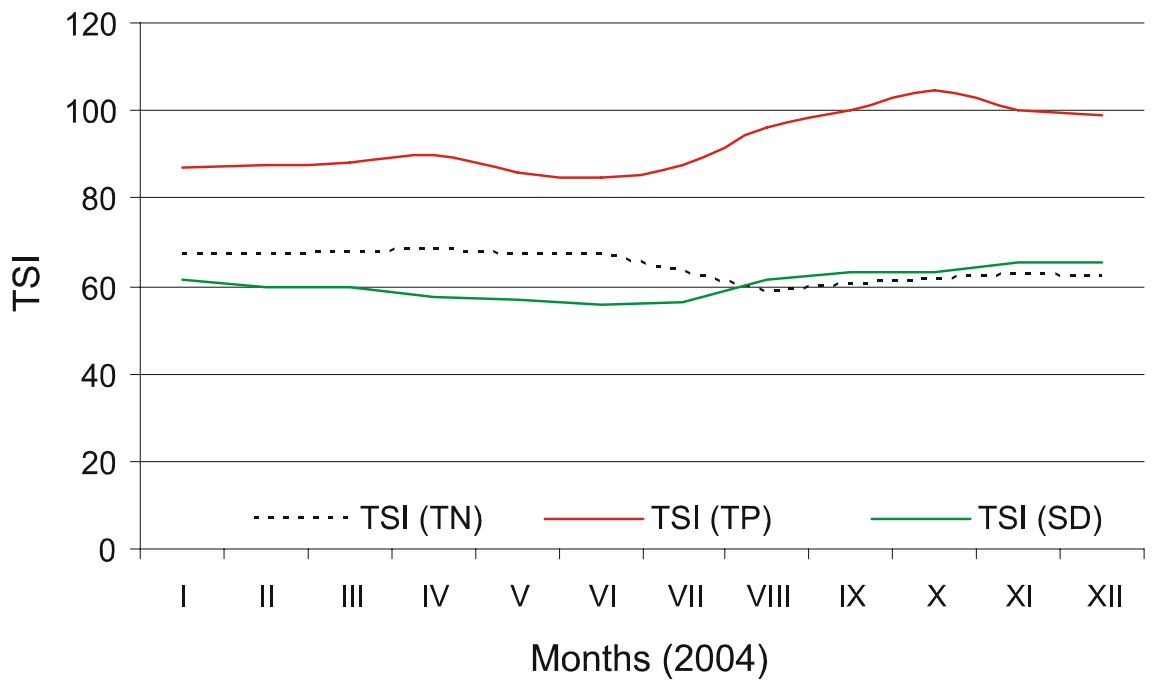

Fig. 11. Seasonal changes of TSI in the discharge zone.

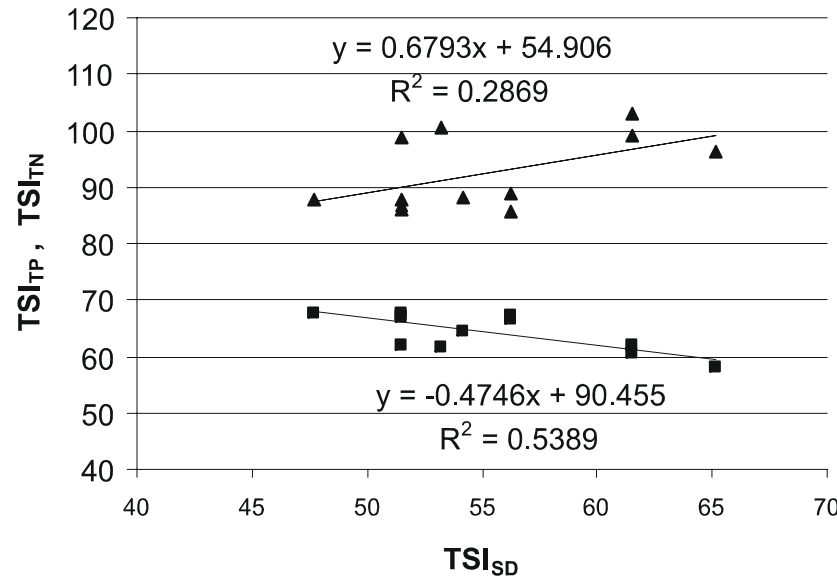

Fig. 12. Relationship between $T S I_{S D}$ and $T S I_{T P}$ (triangles) and $T S I_{T N}$ (boxes) in the dam zone in 2004. 


\section{CONCLUSIONS}

The water temperature in Rybnik Reservoir depends on the air temperature and on the flow and temperature of the discharged heated water. The artificially elevated water temperature prevented surface ice cover. The lowest water temperature observed in winter was $3.8^{\circ} \mathrm{C}$.

Water layer skimming was observed and temperature differences between the surface and bottom layers occurred in the warm, upper part of the reservoir, while in the dam sector, temperature equalization was observed in the water column as an effect of intensive water mixing.

The observed lack of dissolved oxygen depletion was the result of intense water mixing, in spite of high water temperature and low oxygen solubility. Water blooms caused oxygen supersaturation in the water surface layer. The value of the trophic state index (TSI) calculated permits classifying Rybnik Reservoir as a eutrophic basin.

\section{REFERENCES}

Amarasinghe P.B., Vijverberg J., 2002, Primary production in a tropical reservoir in Sri Lanka, Hydrobiologia, 487: 85-93

EEI, 1996, Environmental Directory of US Power Plants, 1996, Edison Electric Institute, Washington, DC

Bloemkolk J.W., Van der Schaff R.J., 1996, Design alternatives for the use of cooling water in the process industry: minimization of the environmental impact for cooling systems, J. Cleaner Prod., 4(1): 21-27

Carlson R.E., 1977, A trophic state index for lakes. Limnology and Oceanography, 22: 361-69.

Gołdyn R., Joniak T., Kowalczewska-Madura K., Kozak A., 2003, Trophic state of a lowland reservoir during 10 years after restoration, Hydrobiologia, 506-509: 759-65.

Hense I., Beckmann A., 2006, Towards a model of cyanobacteria life cycle-effects of growing and resting stages on bloom formation of $N_{2}$-fixing species, Ecological Modelling, 195: 20518

Kostecki M., 2001, The limnological characteristic of the Plawniowice dam-reservoir (Upper Silesia, Poland) - Thermal and oxygen conditions after 23years of exploatation, Arch. Ochr. Środ., 27(2): 97-124 (in Polish, summary in English )

Kostecki M., 2004, Anthropopression on the formation of the thermal structure on the Rybnik dam-reservoir, Arch. Ochr. Środ., 30 (4): 41-52 (in Polish, summary in English)

Kostecki M., 2005, Specificity of the thermal conditions of the „Rybnik” water reservoir as the effect of heated waters discharge, Prob. Ekol., 3(51): 151-61 (in Polish, summary in English)

Kratzer C.R., Brezonik P.L., 1981, A Carlson-type trophic state index for nitrogen in Florida lakes. Water. Res. Bull., 17: 713-15.

Rai A.K., 2000, Limnological characteristics of subtropical Lakes Phewa, Begnas, and Rupa in Pokhara Valley, Nepal, Limnology, 1: 33-46

Standard Methods for Examination of Water and Wastewater. 15th ed., 1981, American Public Health Association, 1015 18th Street, N.W., Washington, D.C. 20036

Veil J.A., Puder M.G, Littleton D.J., Moses D.O., 1999, Cooling water use patterns at US nonutility electric generating facilities, Environmental Science \& Policy, 2: 477-87 
Veil J.A., 2000, Potential impacts of 316(b) regulatory controls on economics, electricity reliability, and the environment, Environmental Science \& Policy, 3: S1-S6

Zdanowski B., Wilkońska H., Ciepielewski W., Socha D., Swiątecki A., Tunowski J., 1991, Three decades of the Konin lakes - importance and human consciousness, Komunikaty Rybackie, 4: 2-7 (in Polish) 